\title{
Evaluation of Hemoglobin Concentration in Pregnancy and Correlation with Different Altitude: A Study from Balochistan Plateau of Pakistan
}

\author{
Zubaida Umar ${ }^{1}$, Mahmood Rasool ${ }^{2, *}$, Muhammad Asif ${ }^{3}$, Sajjad Karim $^{2}$, Arif Malik ${ }^{4}$, \\ Gohar Mushtaq ${ }^{5}$, Mohammad A. Kamal ${ }^{6}$ and Arsala Mansoor ${ }^{1}$ \\ ${ }^{I}$ Bolan Medical College, Quetta, Pakistan \\ ${ }^{2}$ Center of Excellence in Genomic Medicine Research (CEGMR), King Abdulaziz University, Jeddah, Saudi Arabia \\ ${ }^{3}$ Department of Biotechnology and Informatics, BUITEMS, Quetta, Pakistan \\ ${ }^{4}$ Institute of Molecular Biology and Biotechnology (IMBB), The University of Lahore, Lahore, Pakistan \\ ${ }^{5}$ Department of Biochemistry, College of Science, King Abdulaziz University, Jeddah, Saudi Arabia \\ ${ }^{6}$ King Fahd Medical Research Center, King Abdulaziz University, Jeddah, Saudi Arabia
}

\begin{abstract}
Background: Anemia refers to a condition having low hemoglobin concentration. Anemia is considered a major risk factor for unfavorable pregnancy outcomes. This is the first study describing the pattern of hemoglobin concentration during pregnancy and its relationship to areas of high and low altitudes in Balochistan (the largest of Pakistan's four provinces). The main objective of this study was to observe hemoglobin levels and prevalence of anemia among pregnant women living in the high or low altitude areas of Balochistan.

Methods: A randomized survey was conducted and blood samples were collected from 132 healthy full term pregnant women subjects and 110 unmarried females. The subjects of the current study were selected from two different areas of Balochistan (Quetta and Uthal). Hemoglobin levels of the subjects were analyzed on Microlab 300 by Merck kit. Dietary status of the subjects was assessed based on simplified associated food frequency questionnaire. The factors effecting hemoglobin in full term pregnancy at different altitudes were multi gravidity/parity (increased number of pregnancies/children), age, socio-economic and educational status.

Results: Anemia was highly prevalent in low-altitude region (68.33\%). We found statistically significant difference in mean hemoglobin level at high-altitude region $(11.81 \pm 1.02)$ and low-altitude region $(10.20 \pm 1.28)$ in pregnant females of Balochistan plateau ( $\mathrm{P}<0.001)$. Higher maternal age (> 35 years) has shown significantly higher anemic frequency at both high $(57.89 \%$; $\mathrm{p}$ < 0.002) and low $(41.46 \%$; $\mathrm{p}=0.067)$ altitudes. A balanced-diet that is rich in meat products has also shown significant correlation with reduced incidences of anemia among pregnant women at both altitudes.

Conclusion: Hemoglobin concentration increases in the body with elevated altitudes and, thus, anemia was less frequent at high-altitude region. Factors affecting hemoglobin concentration in full term pregnancy at different altitudes included old maternal age, low body-mass index, education and diet.
\end{abstract}

Keywords: Anemia, altitude, diet, hemoglobin, pregnancy.

\section{INTRODUCTION}

Anemia is a common health problem during pregnancy all around the world [1-2], in developing as well as developed countries [3-5]. The World Health Organization has defined anemia as a condition in which hemoglobin content of blood is lower than the normal, i.e., $11 \mathrm{~g} / \mathrm{dL}$ of blood, as a result of deficiency of one or more essential nutrients $[3,6,7]$. The prevalence of anemia is $30.2 \%$ in

*Address correspondence to this author at the Center of Excellence in Genomic Medicine Research (CEGMR), Post Box No. 80216, King Abdulaziz University, Jeddah 21589, Saudi Arabia. Tel: +966-6401000; Ext: 25479; Fax: +966-6952521; E-mail: mahmoodrasool@yahoo.com non-pregnant women and $41.8 \%$ in pregnant woman around the world [8].

Anemia in pregnancy is a serious condition that contributes to increased rates of maternal and fetus morbidity as well as mortality. Patients of anemia show various symptoms such as generalized weakness, breathlessness and perceived paleness or change in skin colour (especially nails and lips colour turned to yellow), rapid heartbeat, headache and irritability [6].

At higher altitudes (above 1000 meters) from the sea level, the partial pressure of oxygen is decreased in the atmosphere leading to lower oxygen saturation of the blood. Thus, hemoglobin levels increase as an adaptive response to 
the decreased partial pressure of oxygen and reduced oxygen saturation of blood [1,9]. Hemoglobin levels vary with age, sex, nutrition, socio-economic status, ethnicity and race [10]. Aggravating factors that increase the risk of anemia include poor diet, low socio-economic status [11-13], insufficient health facilities and lack of education in rural areas [14], lack or deficiency of some essential elements (like, iron, vitamin B12 and folic acid which are essential for hemoglobin synthesis) [15], vitamin A deficiency [16, 17], recurrent pregnancies, suppression of RBC production due to bone marrow defects, rheumatoid arthritis, tuberculosis and chronic blood loss, worm infestation $[8,11,12]$ and malaria $[18,19]$. High levels of hemoglobin concentrations, i.e., less than $14.5 \mathrm{~g} / \mathrm{dL}$ are associated with hypertension and pregnancy-induced hypertension. Growth retarding effects are also observed among high altitude dwellers [20].

To date no scientific study has been conducted describing the pattern of hemoglobin concentration during pregnancy and its relationship with altitude in the regions of Baluchistan. This present cross-sectional study was designed to determine and compare the hemoglobin levels among pregnant as well as unmarried females living at high-altitude region (HA) (Quetta City) and low-altitude region (LA) (Uthal City). This current study also assessed the effects of other factors such as socioeconomic status, education, gravidity, body-mass index (BMI), smoking and maternal age on hemoglobin concentration.

\section{MATERIALS AND METHODS}

\section{Setting and Study Area}

The study was conducted in Quetta and Uthal cities of Balochistan plateau of Pakistan. This plateau has an average altitude of 2,000 feet and the mountains of this region attain the average height of 6,000-11,000 feet. Mean altitudes of Quetta city (HA) and Uthal city (LA) are 1,675 meters and 24 meters above the sea level. The conditions of the plateau are dry and arid. The people here usually live nomadic life and have adapted themselves to the life of high altitude and dry environment. A randomized survey was conducted and samples were collected at the Bolan Medical Complex Hospital and Sandeman Civil Hospital, Quetta and at the Uthal Medical Centre, Uthal, Balochistan, Pakistan. Healthy, pregnant women subjects were selected from the same region.

\section{Sample and Data Collection}

In the present hospital-based study, 132 healthy pregnant women ( 72 from HA and 60 from LA) and 110 unmarried (non pregnant) female (55 from HA and 55 from LA) were enrolled from the cities of Balochistan, Pakistan, between November 2009 to November 2011. The subjects were interviewed by professionally trained lady doctors, using a standard and detailed questionnaire that include participant's name, age, gravidity, clinical signs and symptoms, education, monthly income and living style, ethnicity, smoking or tobacco chewing habit and dietary intake. On the basis of ages ranging from 18-45 years, the subjects were divided into young (15-25), middle (26-35) and old (36-45) age groups. Based on monthly income, the subjects were distributed into three classes: upper class (\$300 US dollars), middle class ( $\$ 100-299$ US dollars) and poor class $(<\$ 100$ US dollars). In terms of literacy level, the subjects were divided into illiterate and literate (applying minimum 5 years of primary education as the cutoff). Smoking habit was evaluated based on whether the subject used tobacco or its products like cigarette, snuff (naswar) or gutka.

The general characteristics of pregnant and anemic females from HA and LA areas were shown in Table 1. Dietrelated information, food type and its frequency of intake were collected to estimate the specific nutrient intake by the subjects and the association of those parameters with anemia (Table 3). Clinical signs and symptoms including breathlessness, pallor of skin, pale conjunctiva, and koilonychea (spoon-shaped nails) were recorded (Table 4). Maternal weight $(\mathrm{kg})$, height $(\mathrm{cm})$ and upper mid arm circumference (UMAC) $(\mathrm{cm})$ were also measured. Weights were recorded in kilogram $(\mathrm{kg})$ with sensitivity of $0.25 \mathrm{~kg}$ (Weighing Balance, Tanita, China) and heights were recorded in centimeters. Maternal BMI is calculated as weight in kilograms divided by square of height in meters. BMI less than 18.5 was categorized as underweight, 18.524.9 as normal, and $>25$ as over-weight (Stephen, 2009). The upper mid arm circumference of the upper left arm was measured at the midpoint between the tip of the shoulder and tip of the elbow. Mean and standard deviations of BMIrelated information are summarized in Table $\mathbf{5}$.

\section{Blood Collection and Laboratory Investigation}

Skin was cleaned thoroughly and sterilized with $70 \%$ isopropyl alcohol swab (Kandall HealthCare, USA) and dried before withdrawing $2 \mathrm{~mL}$ peripheral blood using $5 \mathrm{cc}$ disposable syringe (Becton Dickinson Pak) from enrolled subjects. The blood was transferred to ethylenediamine tetra acetic acid (EDTA) coated purple-top test tube. The blood was mixed in the test tubes with 5 complete inversions and tubes were marked with codes and immediately taken to the laboratory for investigation. Hemoglobin concentrations were analyzed with the Chemical Analyzer (Microlab 300) by using Merck Kit. Hemoglobin derivatives in blood are converted quantitatively to hemoglobin cyanide (cyanomethoglobin) and measured on photometer.

\section{Hb Adjusted for Altitude}

Three altitude correction methods, the CDC, 1994, Dirren et al., 1996 and Dallman et al., 1980 were used in our study to adjust the hemoglobin concentration for altitude. They can be expressed as: $\mathrm{CDC}$ correction method: $\Delta \mathrm{Hb}=$ $-0.032 \times(\mathrm{Alt})+0.022 \times(\mathrm{Alt}) 2$, where $\delta \mathrm{Hb}$ is the increment of $\mathrm{Hb}$ by increased altitude above sea level, and Alt is the altitude (1000 m×3.3); Dirren et al., correction method: $\mathrm{Hb}$ sea-level $=\mathrm{Hb}$ measured $-3.44 \times(\mathrm{e}(0.000633 \times \mathrm{Alt})-1)$, where $\mathrm{Hb}$ sea level stands for the concentration after adjustment, and Alt for altitude (m); and in Dallman et al., correction method: $\mathrm{Hb}$ increased by $4 \mathrm{~g} / \mathrm{L}$ per $1000 \mathrm{~m}$ elevation above sea level [21-23]. 


\section{Data Analysis}

Sigmastat 3.5 and SPSS ver.18 were used for statistical analysis. Results were expressed by mean and standard deviation. Between the two groups, all results were checked by unpaired t-test and one way ANOVA. $P$ values $<0.05$ were considered as statistical significant.

\section{RESULTS}

A total of 242 subjects were enrolled in this study: 132 pregnant (72 from HA and 60 from LA) and 110 unmarried females (55 from HA and 55 from LA). According to the World Health Organization, anemia is defined as a condition in which the hemoglobin level is lower than the normal. Based on hemoglobin levels, the subjects were categorized as anemic $(<11 \mathrm{~g} / \mathrm{dL})$ or non-anemic $(>12 \mathrm{~g} / \mathrm{dL})$. Among the pregnant women, $26.39 \%$ were found to be anemic versus $73.63 \%$ non-anemic at HA while $68.33 \%$ were found to be anemic versus $31.67 \%$ non-anemic at LA (Table 1). Among the unmarried females, $5.45 \%$ and $21.82 \%$ were anemic at HA and LA, respectively. Higher percentage of non-anemic subjects $(94.55 \%)$ at HA clearly indicates body's adaptation to high altitude by increased concentrations of hemoglobin.

The ages of the subjects ranged from 18-45 years. At $\mathrm{HA}$, the mean age of pregnant and unmarried females was 31.83 and 24 years whereas at LA, it was 30.70 and 23 years, respectively. The age group distribution was as follows: young (< 25 years), middle (26-35 years) and old (> 35 years). It was observed that old age group females were more prone to anemia $(52.38 \%)$, followed by young $(27.27 \%)$ and the least number of females were found in the middle age group (6.90\%), showing high level of significance $(\mathrm{p}<0.002)$ at high altitude. Similar trend was also recorded at low altitude ( $<0.07)$, with $85.00 \%$ anemic among the old age group, followed by young $(70.00 \%)$ and middle $(50.00 \%)$ age group females (Table 1). We did not found any significant correlation with maternal age across the altitudes ( $\mathrm{p}$ value 0.7062 ).

Recurrent pregnancy is reported to be associated with decreased hemoglobin. We found anemia in $20.00 \%$ and $28.85 \%$ of subjects with primi-gravida and multi-gravida at HA, respectively. In addition, it was found that $69.23 \%$ and $68.08 \%$ primi-gravida and multi-gravida women were anemic at low altitude. The results from our study have shown that multi-gravida pregnant females have higher risk of anemia. However, we did not find any significant correlation between gravidity and hemoglobin concentration at any altitude (Table 1).

Socioeconomic and lifestyle data were obtained by a questionnaire that was administered in Quetta and Uthal. It elicited information on occupation, family income, education, smoking and tobacco chewing. Socioeconomic status had also shown to play a role in anemia frequency, with majority of the anemic subjects coming from middle/poor class families: $18 / 19$ at $\mathrm{HA}$ and $41 / 41$ at LA. Anemia prevalence in middle/poor class might be due to non-availability of the essential elements in their diet (Table 1).
Lack of education is one of the major risk factors for anemia. In general, uneducated (illiterate) females are unaware of balanced diet and hygienic conditions, which results in anemia and many other diseases. The results of this study demonstrate that most of the anemic subjects were illiterate in Uthal city (78.26\%, p value < 0.006$)$. Likewise, in Quetta city, 17 out of 19 anemic pregnant subjects were illiterate (Table 1). Full term pregnant females were categorized according to their tobacco use or smoking habits. Analysis of smoking frequency revealed that $62.50 \%$ smokers in Quetta and $86.96 \%$ smokers in Uthal city were anemic, showing strong correlation between smoking and anemia at HA $(p<0.02)$ and LA $(p<0.02)$ (Table $\mathbf{1})$.

Table 2 shows the hemoglobin levels of all subjects selected from high and low altitude. We found statistically significant difference in the mean hemoglobin levels among all groups: A and B, A and C, C and D, B and D. Our results confirmed that mean hemoglobin levels of pregnant as well as non-pregnant women were positively correlated with living at high or low altitude, i.e. $11.81 \pm 1.02$ (HA) vs $10.20 \pm 1.28(\mathrm{LA})(\mathrm{P}<0.001)$ in pregnant women while $14.75 \pm 2.06$ (HA) vs $13.4 \pm 2.34(\mathrm{LA})(\mathrm{P}<0.002)$ in nonpregnant women.

Table 3 shows the effects of diet and food consumption frequency on anemia incidences among pregnant women of HA and LA. Our results demonstrate a significant correlation between meat consumption and increased hemoglobin concentration $(\mathrm{p}<0.01)$, that is, subjects consuming more beef/mutton or poultry products in their food had less anemic incidences whereas subjects with low or no intake of meat products more often suffered from anemia at both Quetta and Uthal city.

All the selected subjects were interviewed and examined for the signs and symptoms of anemia. It was observed that signs and symptoms were not the same in all pregnant females. Table $\mathbf{4}$ shows that at high altitude, the incidence of symptoms such as breathlessness, palpitation, pallor, pale conjunctiva and koilonychias were $27.77 \%, 18.05 \%$, $25.00 \%, 18.05 \%$, and $4.16 \%$ respectively, among all pregnant women subjects in general while higher incidences of the same symptoms were recorded among anemic pregnant women with a frequency of $60 \%, 61.54 \%, 55.56 \%$, $76.92 \%$, and $100 \%$ respectively. Except koilonychias symptom at low altitude, all studied signs and symptoms of anemia showed high significant correlation with anemia $(\mathrm{p}<0.05)$.

Table 5 shows some important basic characteristics of pregnant women at high and low attitudes. Pregnant women at high altitude had significantly higher mean BMI $(\mathrm{P}<0.001)$ and weight $(\mathrm{P}<0.009)$ but significantly lower mean UMAC $(\mathrm{P}<0.001)$. No statistical significance was found in systolic and diastolic blood pressure of pregnant women at HA and LA.

\section{DISCUSSION}

Anemia was more prevalent in LA Uthal area (68.33\%) while results obtained from HA Quetta city showed lesser incidences of anemia (26.39\%). We found 30 subjects 
(41.65\%) of HA population had high hemoglobin concentration in comparison to $7(11.67 \%)$ among the low altitude subjects. Studies have confirmed that at higher altitudes, i.e. above 1000 meters, hemoglobin levels increase as an adaptive response to hypoxic atmosphere, to the decreased partial pressure of oxygen and decreased oxygen saturation of blood [24-25]. Previous results have confirmed that mean hemoglobin levels were higher in pregnant women living at high altitudes, showing a positive association between hemoglobin and altitude $[1,26]$. Our results support findings from previous studies that concentrations of hemoglobin are elevated in high-altitude populations.

Maternal age, multi parity, low BMI, and cigarette smoking have been reported in literature as risk factors for anemia during pregnancy [12]. Bhargawa et al., (2001) found that hemoglobin levels decrease with age and hemoglobin status is positively associated with height and UMAC (where height is a sign of good early nutritional state, while UMAC is dependent on the body mass). Our results showed that anemia was present in all maternal age groups with high prevalence in old maternal age, $52.38 \%$ for HA and $85 \%$ for LA [27].

Sharma et al., (2003) concluded that anemia in pregnancy is highly prevalent and it might be dependent on nutrition intake and mother's health, genetic factors, and socioeconomic culture. Education is also an important factor since educated females are aware of anemia and the importance of nutrition during pregnancy. We found anemia to be common in illiterate subjects, $17 / 19$ and $36 / 41$ at HA and LA respectively. Agarwal et al., (2008) found that anemic mothers were illiterate and belonged to poor socioeconomic backgrounds. Our finding also matches with previous finding as $66.67 \%$ of LA anemic mothers belonged to poor socioeconomic backgrounds. In most underdeveloped and in many developed countries, iron deficiency is the main cause of anemia among women and studies have shown that iron supplementation can prevent or correct the anemia $[3,28]$. Our study supports the statement that low socio economic status, poor diet and nutritional deficiencies are associated with anemia $[4,14,29]$.

\section{CONCLUSION}

Anemia is very much prevalent worldwide and it happens mainly during pregnancy. Hemoglobin concentration is significantly correlated with altitude, increasing with elevated altitude. BMI (under weight) and smoking are also significantly related to altitude with high anemic incidence rates at LA. Maternal age is directly related to anemia. Occurrence of anemia is common in illiterate females of poor populations. Balanced diet with adequate meat products may reduce the risks of anemia among pregnant women.

\section{APPENDIX}

Table 1. General Characteristics of anemic pregnant women residing at high and low altitudes.

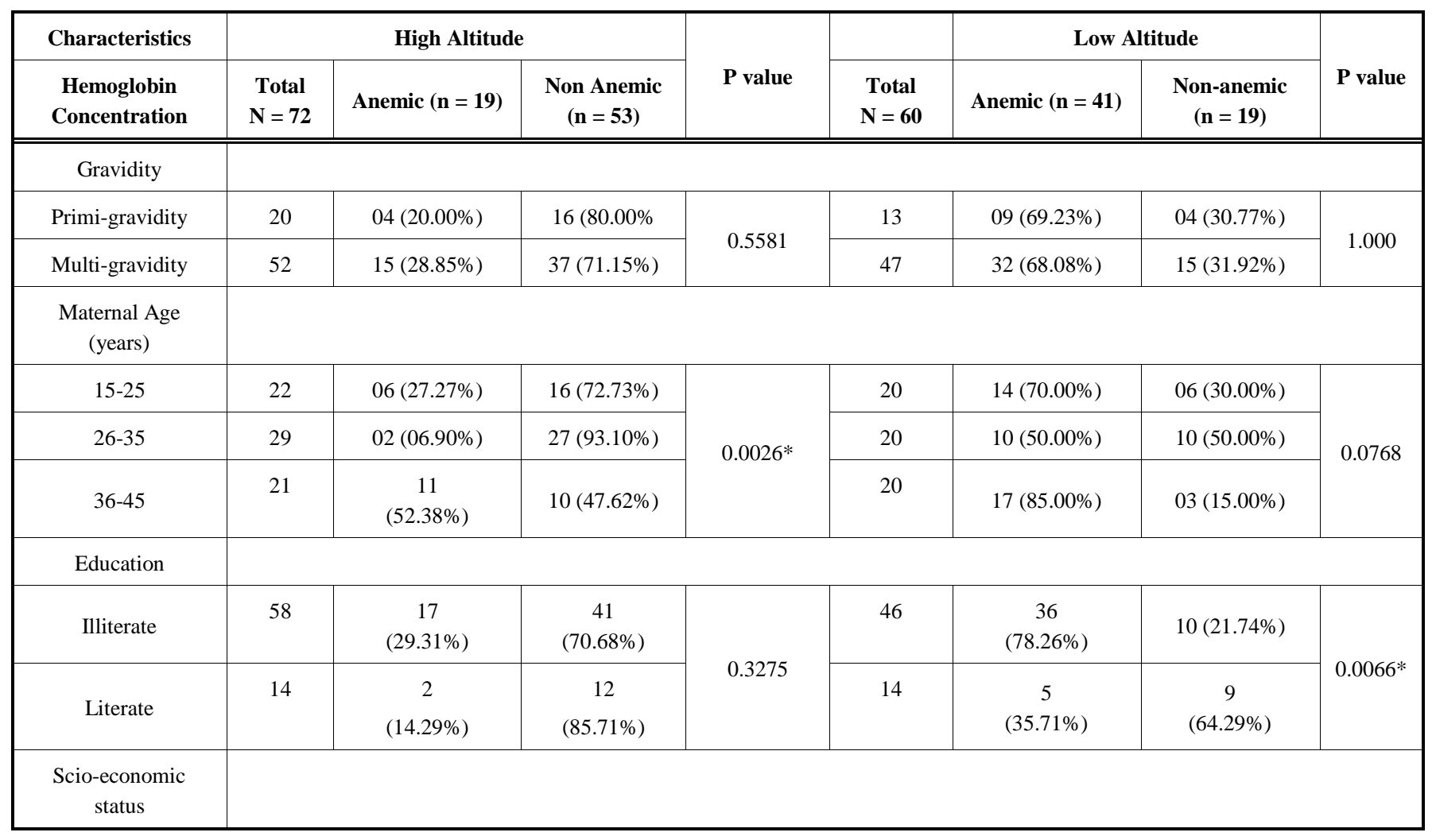


Table 1. Contd.....

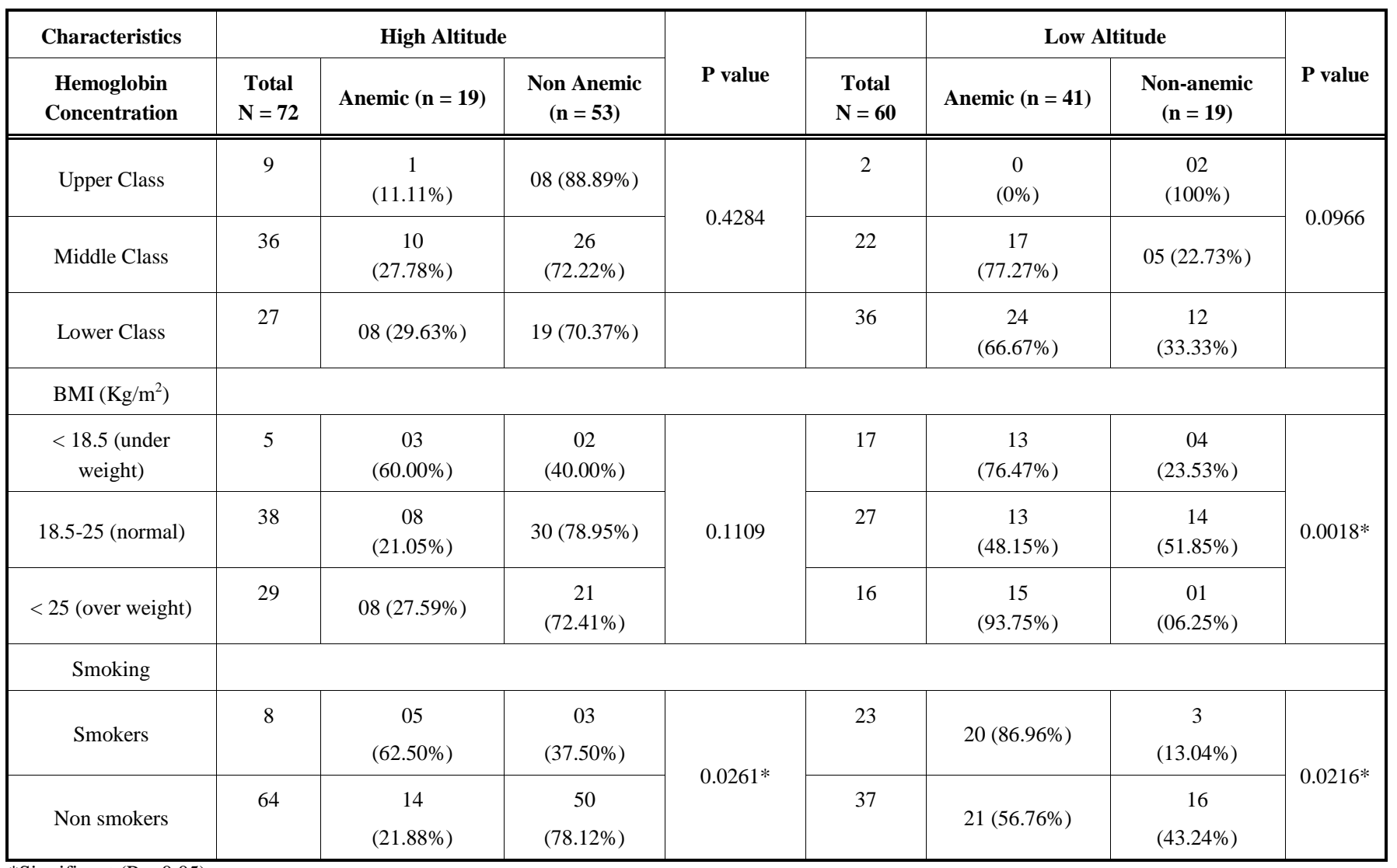

*Significant $(\mathrm{P}<0.05)$

Table 2. Comparative cross-sectional statistical analysis of Hemoglobin levels in pregnant women and unmarried females at high and low altitudes.

\begin{tabular}{|c|c|c|c|}
\hline Parameters & N & Mean + Std & P Value \\
\hline \hline Group A & 72 & $11.81 \pm 1.02$ & $0.001^{*}$ \\
Group B & 60 & $10.20 \pm 1.28$ & $0.001^{*}$ \\
\hline Group A & 72 & $11.81 \pm 1.02$ & $14.75 \pm 2.06$ \\
Group C & 55 & $14.75 \pm 2.06$ & $0.002^{*}$ \\
\hline Group C & 55 & $13.40 \pm 2.34$ & $0.001^{*}$ \\
Group D & 55 & $10.20 \pm 1.28$ & $13.40 \pm 2.34$ \\
\hline Group B & 60 & 55 & 0 \\
\hline
\end{tabular}

*Significant $(\mathrm{P}<0.05)$

$\mathrm{A}=$ Hemoglobin level in pregnant women at high altitude

$\mathrm{B}=$ Hemoglobin level in pregnant women at low altitude

$\mathrm{C}=$ Hemoglobin level in unmarried women at high altitude

$\mathrm{D}=$ Hemoglobin level in unmarred women at low altitude

Table 3. Dietary nature and anemia incidences among pregnant women at high and low altitudes.

\begin{tabular}{|c|c|c|c|c|c|c|c|c|c|}
\hline $\begin{array}{l}\text { Dietary } \\
\text { Nature }\end{array}$ & Frequency & \multicolumn{4}{|c|}{ High Altitude } & \multicolumn{4}{|c|}{ Low Altitude } \\
\hline $\begin{array}{l}\text { Beef/ } \\
\text { Mutton }\end{array}$ & $\begin{array}{l}\text { Don't or } \\
\text { low }\end{array}$ & $12(16.67 \%)$ & $\begin{array}{c}07 \\
(58.33 \%)\end{array}$ & $05(41.67 \%)$ & $0.011^{*}$ & $45(75.00 \%)$ & $\begin{array}{c}35 \\
(77.78 \%)\end{array}$ & $10(22.22 \%)$ & $0.010^{*}$ \\
\hline
\end{tabular}


Table 3. Contd.....

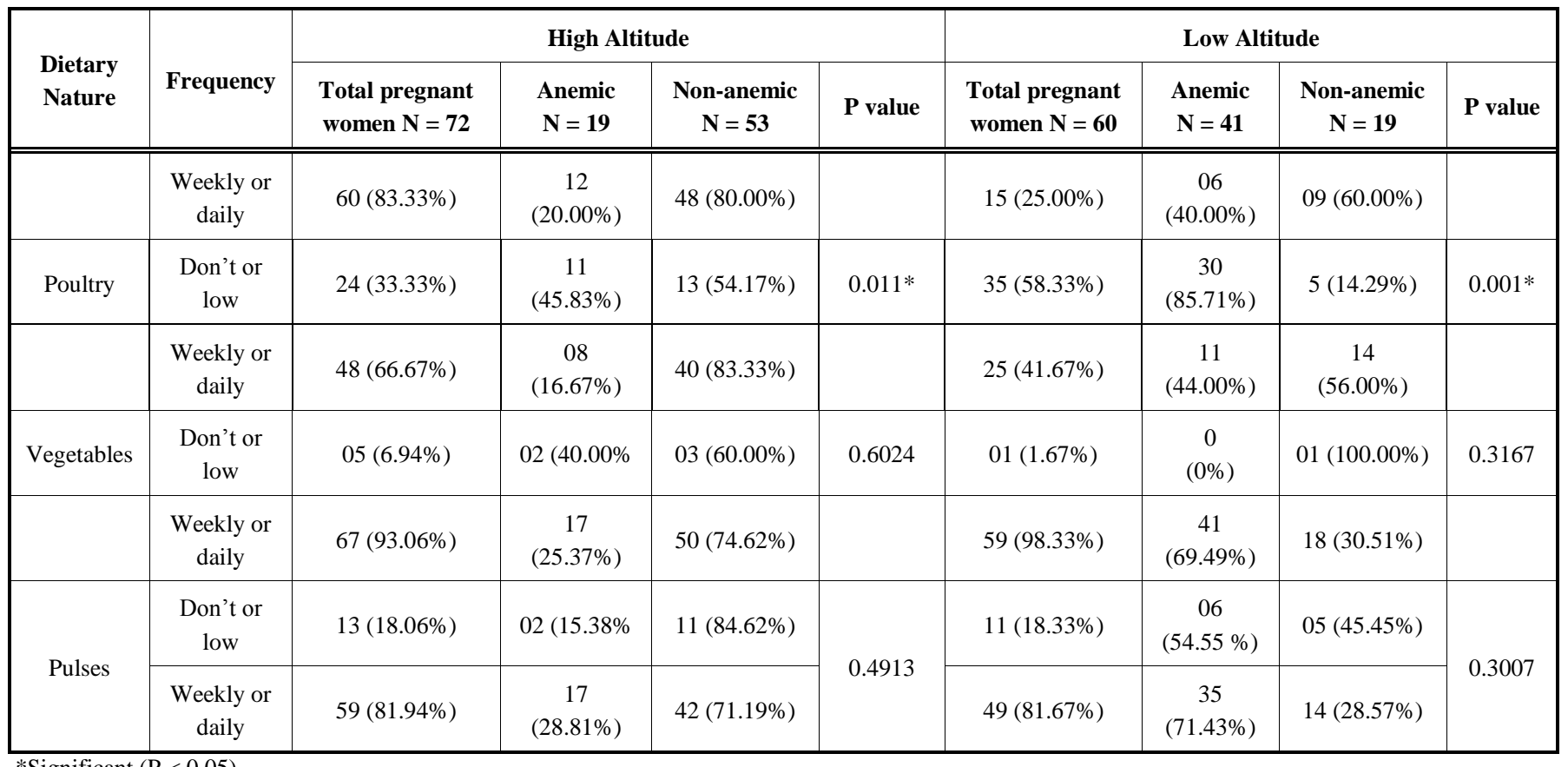

*Significant $(\mathrm{P}<0.05)$

Table 4. Signs and symptoms of anemia among pregnant females of Balochistan.

\begin{tabular}{|c|c|c|c|c|c|c|c|c|c|}
\hline Symptoms & Status & \multicolumn{4}{|c|}{ High Attitude $N=72$} & \multicolumn{4}{|c|}{ Low Attitude $N=60$} \\
\hline \multirow{2}{*}{ Breathlessness } & + & $20(27.77 \%)$ & $12(60.00 \%)$ & $8(40.00 \%)$ & \multirow{2}{*}{$0.0002 *$} & $23(38.33 \%)$ & $22(95.65 \%)$ & $1(4.35 \%)$ & \multirow{2}{*}{$0.0004 *$} \\
\hline & - & $52(72.22 \%)$ & $7(13.46 \%)$ & $45(86.54 \%)$ & & $37(61.67 \%)$ & $19(51.35 \%)$ & $18(48.65 \%)$ & \\
\hline \multirow{2}{*}{ Palpitation } & + & $13(18.05 \%)$ & $8(61.54 \%)$ & $5(38.46 \%)$ & \multirow{2}{*}{$0.0035^{*}$} & $20(33.33 \%)$ & $19(95.00 \%)$ & $1(5.00 \%)$ & \multirow{2}{*}{$0.0013 *$} \\
\hline & - & $59(81.95 \%)$ & $11(18.64 \%)$ & $48(81.36 \%)$ & & $40(66.67 \%)$ & $22(55.00 \%)$ & $18(45.00 \%)$ & \\
\hline Pallor & + & $18(25.00 \%)$ & $10(55.56 \%)$ & $8(44.44 \%)$ & $0.0038^{*}$ & $29(48.33 \%)$ & $26(89.66 \%)$ & $3(15.79 \%)$ & $0.0008^{*}$ \\
\hline \multirow{2}{*}{ Pale Conjunctiva } & + & $13(18.05 \%)$ & $10(76.92 \%)$ & $3(23.08 \%)$ & \multirow{2}{*}{$0.0001^{*}$} & $39(65.00 \%)$ & $37(94.87 \%)$ & $2(05.13 \%)$ & \multirow{2}{*}{$0.0001 *$} \\
\hline & - & $59(81.95 \%)$ & $9(15.25 \%)$ & $50(84.75 \%)$ & & $21(35.00 \%)$ & $4(19.05 \%)$ & $17(80.95 \%)$ & \\
\hline \multirow{2}{*}{ Koilonychias } & + & $03(4.16 \%)$ & $03(100 \%)$ & $0(0 \%)$ & \multirow{2}{*}{$0.0162^{*}$} & $07(11.67 \%)$ & $07(100 \%)$ & $0(0 \%)$ & \multirow{2}{*}{0.0859} \\
\hline & - & $69(95.84 \%)$ & $16(23.19 \%)$ & $53(76.81 \%)$ & & $53(88.33 \%)$ & $34(64.15 \%)$ & $19(35.85 \%)$ & \\
\hline
\end{tabular}


Table 5. Some other important study parameters.

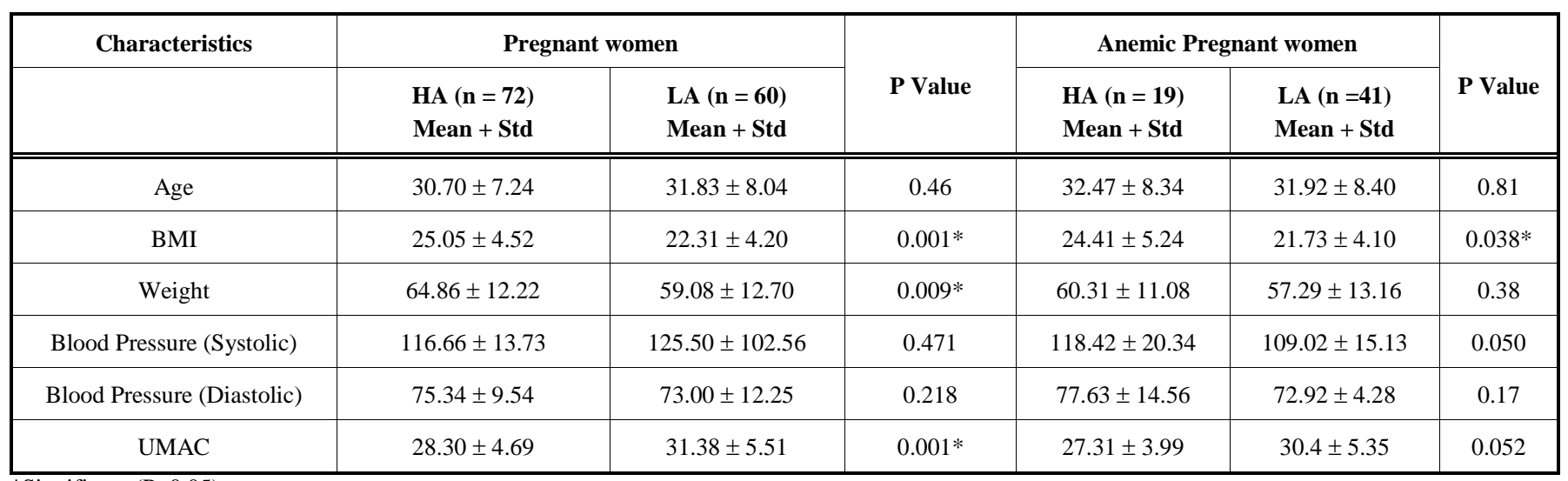

*Significant $(\mathrm{P}<0.05)$

\section{ABBREVIATIONS}

$\begin{array}{lll}\text { LA } & = & \text { low-altitude region } \\ \text { HA } & = & \text { high-altitude region } \\ \text { BMI }= & \text { body-mass index } \\ \text { UMAC } & \text { upper mid arm circumference }\end{array}$

\section{CONFLICT OF INTEREST}

The authors declare no conflict of interest.

\section{ACKNOWLEDGEMENTS}

Declared none.

\section{AUTHORS' CONTRIBUTIONS}

$\mathrm{ZU}^{1}$ has performed the experiments. $\mathrm{MA}^{3}$ and $\mathrm{AM}^{4}$ have supervised the study. $\mathrm{MR}^{2}$ and $\mathrm{AM}^{7}$ have designed the study. $\mathrm{MA}^{3}$ and $\mathrm{MR}^{2}$ have written the manuscript. $\mathrm{SK}^{2}, \mathrm{GM}^{5}$ and MAK $^{6}$ analyzed the data and reviewed the manuscript critically.

\section{REFERENCES}

[1] Cohan, J.H.; Hass, J.D. Hemoglobin concentration factors for estimating the prevalence of Iron Deficiency Anemia in pregnant women residing at high altitudes in Bolivia. Pan. Am. J. Public Health, 1999, 6(6), 392-399.

[2] Kisioglu, N.N.; Ozturk, M.; Cakmak, Z.A.; Ozguner, F. Anemia prevalence and its affecting factors in pregnant women of Isparta Province. Biomed. Res., 2004, 16(1), 11-14.

[3] Jaleel, R.; Khan, A. Severe anemia and adverse pregnancy outcome. J. Surg. Pakistan, 2008, 13(4), 147-150.

[4] Agarwal, T.; Kochar, G.K.; Goel, S. Impact of iron supplementation on anemia during pregnancy. Ehno. Med., 2008, 2(2), 149-151

[5] Singla, P.N.; Tyagi, M.; Kumar, A.; Dash, D.; Shankar, R. Fetal growth in maternal anemia. J. Trop. Pediat. 1997, 43, 89-92.

[6] Haidar, J.A.; Pobocik, R.S. Iron deficiency anemia is not a rare problem among women of reproductive ages in Ethopia: a community based cross sectional study. BMC Blood Disord., 2009, 9:7.

[7] Sulbha V. Anemia and pregnancy. J. Diet. Nutr., 1999, 26(6), 5-27.

[8] Zhou, X.; Yan, H.; Xing, Y.; Dang, S.;Zhuoma, B.; Wang, D. Evaluation of a portable hemoglobin photometer in pregnant women in a high altitude area: a pilot study. BMC Public Health, 2009, 9, 228.
[9] Xing, Y.; Yan, H.; Dang, S.; Zhuoma, B.; Zhou, X.; Wang, D Hemoglobin levels an anemia evaluation during pregnancy in the highlands of Tibet: at hospital based study. BMS Public Health, $\mathbf{2 0 0 9}, 9,336$.

[10] Johnson-Spear, M.A.; Yip, R. Hemoglobin difference between black and white women with comparable iron status: justification for race-specific anemia criteria. Am. J. Clin. Nutr., 1994, 60, $117-121$.

[11] Dreyfuss, M.L.; Stoltzfus, R.J.; Shrestha, J.B.; Pradhan, E.K.; LeClerg, S.C.; Khatry, S.K.; Shrestha, S.R.; Katz, G.; Albonico, M.; Wesj, K.P. Hookworms, malaria and vitamin A deficiency contribute to anemia and iron deficiency among pregnant women in plains of Nepal. J. Nutr., 2000, 130, 2527-2536.

[12] Scholl, T.O.; Hediger, M.L.; Fischer, R.L.; Shearer, J.W. Anemia vs. iron deficiency: increased risk of preterm delivery in a prospective study. Am. J. Clin. Nutr., 1992, 55, 985-988.

[13] Sharma, J.B. Soni, D.; Murthy, N.S.; Malhotra, M. Effect of dietary habits on prevalence of anemia in pregnant women of Delhi. $J$. Obst. Gynae. Res., 2003, 29(2), 73-78.

[14] Idris, M.; Anis-ur-Rehman. Iron deficiency anaemia in moderate to severely anaemic patients. J. Ayub Med. Coll., 2005, 17(3), 45-47.

[15] Sifakis, S.; Pharmakides, G. Anemia in pregnancy. Ann NY Acad. Sci., 2000, 900,125-136.

[16] Guyatt, H.L.; Snow, R.W. The epidemiology and burden of plasmodium falciparum-related anemia among pregnant women in sub-Saharan Africa. Am. J. Trop. Med. Hyg., 2001, 64(1-2), 36-44.

[17] Khusun, H.; Yip, R.; Schultink, W.; Dillon, D.H.S. World Health Organization hemoglobin cut-off points for the detection of anemia are valid for an Indonesian population. J. Nutr., 1999, 129, 1669-1674.

[18] Shah, B.K.; Baig, L.A. Association of anemia with parasitic infestation in pregnant Nepalese women: results from a hospitalbased study in Eastern Nepal. J. Ayub Med Coll., 2005, 17(1), 5-9.

[19] Fox, S.I. Human Physiology. $8^{\text {th }}$ ed. McGraw Hill, 2004.

[20] Jensen, G.M.; Moore, L.G. The effect of high altitude and other risk factors on birth weight: independent or interactive effects? Am. J. Public Health, 1997, 87(6), 1003-07.

[21] CDC: Altitude hemoglobin curve and CDC anemia criteria which uses the altitude adjustment Atlanta: Centers for Disease Control and Prevention, 1995.

[22] Dirren, H.; Logman, M.H.; Barclay, D.V.; Freire, W.B. Altitude correction for hemoglobin. Eur. J. Clin. Nutr., 1994, 48, 625-632.

[23] Dallman, P.R.; Siimes, M.A.; Stekel, A. Iron deficiency in infancy and childhood. Am. J. Clin. Nutr., 1980, 33, 86-118.

[24] Ramirez, G.; Bittle, P.A.; Colice, G.L.; Herrere, R.; Agosti, S.J.; Foulis, P.R. The effect of cigarette smoking upon hematological. adaptations to moderately high altitude living. $J$. Wild Med., 1999, 2, 274-286.

[25] Beal, C.M. Andean, Tibetan and Ethiopian patterns of adaptation, to high altitude hypoxia. Integr. Comp. Biol., 2006, 46, 18-24.

[26] Scheinfeldt, L.B.; Soi, S.; Thompson, S.; Ranciaro, A.; Woldemeskel, D.; Beggs, W.; Lambert, C.; Jarvis, J.P.; Abate, D.; Belay, G.; Tishkoff, S.A. Genetic adaptation to high altitude in the Ethiopian highlands. Genome Biol., 2012, 20, 13(1), R1. 
[27] Bhargava, A.; Bouis, H.E.; Scrimshaw, N.S. Dietary Intake and Socioeconomic Factors are Associated with the Hemoglobin Concentration of Bangladeshi Women. J. Nutr., 2001, 131(3), 758-764.

[28] Yip, R. Iron supplementation during pregnancy: is it effective? Am. J. Clin. Nutr., 1996, 63, 853-855.
[29] Rogerson, S.J.; Broke, V.; Chaluluka, E.; Qongwane, C.; Mhango, C.G.; Molyneux, M.E. Malaria and anemia in antenatal women in Bhantyre, Malavi: a twelve month survey. Am. J. Trop. Med.Hyg., 2000, 62(3), 335-340.

(C) Umar et al.; Licensee Bentham Open.

This is an open access article licensed under the terms of the Creative Commons Attribution Non-Commercial License (http://creativecommons.org/licenses/ by-nc/3.0/) which permits unrestricted, non-commercial use, distribution and reproduction in any medium, provided the work is properly cited. 